\title{
Resveratrol protects the retina from I/R injury by inhibiting RGCS apoptosis, glial activation and expression of inflammatory factors
}

\author{
Jinyu Xia1, Xiaolu Yang ${ }^{2}$, Weiai Chen ${ }^{3 *}$ \\ ${ }^{1}$ Department of Gynecology, The Affiliated Hospital of Qingdao University, ${ }^{2}$ Department of Pharmacy, Qingdao Municipal \\ Hospital, Qingdao Municipal Hospital of Shandong Province, ${ }^{3}$ Department of Obstetrics and Gynecology, Huangdao Hospital of \\ Traditional Chinese Medicine, Qingdao, PR China
}

*For correspondence: Email: hinkj0@163.com

Sent for review: 9 April 2020

Revised accepted: 26 May 2020

\begin{abstract}
Purpose: To study the protective effect of resveratrol against retinal injury induced by ischemiareperfusion $(I / R)$, and the underlying mechanism action.

Methods: Retinal I/R injury was established in 72 healthy male SD rats. The rats were assigned to 3 groups: control, model and resveratrol groups, with 24 rats in each group. Pathological changes in retina were determined using H\&E staining. Retinal ganglion cells (RGCs) were counted using fluorescence gold retrograde staining. Western blotting was used to assay the expressions of caspase3, Bax, Bcl-2, GFAP, COX-2 and iNOS. The expressions of COX-2 and iNOS were measured by immunofluorescence.

Results: The retina in the control group was dense and ordered, and its morphology was normal. In contrast, the retina in the model group was thinner, with loose cells and disordered structure. In the resveratrol group, the retina was thicker, the structure was orderly, and the cells were dense. Relative to control, the population of RGCs in model rat retina was significantly reduced, and the expressions of $B c l-2$, Bax, caspase-3, GFAP, COX-2 and iNOS were significantly upregulated $(p<0.05)$. In the resveratrol group, the number of RGCs in the retina was markedly elevated, relative to model rats, and the expressions of Bcl-2, Bax, caspase-3, GFAP, COX-2 and iNOS were significantly decreased ( $p<$ 0.05).

Conclusion: Resveratrol protects the retina from I/R injury in rats by inhibiting RGCs apoptosis, glial activation and expressions of inflammatory factors. Thus, this compound may be potentially suitable for the management of retina damage.
\end{abstract}

Keywords: Resveratrol, RGCs apoptosis, Glial activation, Inflammatory factors, I/R injury

\begin{abstract}
This is an Open Access article that uses a fund-ing model which does not charge readers or their institutions for access and distributed under the terms of the Creative Commons Attribution License (http://creativecommons.org/licenses/by/4.0) and the Budapest Open Access Initiative (http://www.budapestopenaccessinitiative.org/read), which permit unrestricted use, distribution, and
\end{abstract} reproduction in any medium, provided the original work is properly credited.

Tropical Journal of Pharmaceutical Research is indexed by Science Citation Index (SciSearch), Scopus, International Pharmaceutical Abstract, Chemical Abstracts, Embase, Index Copernicus, EBSCO, African Index Medicus, JournalSeek, Journal Citation Reports/Science Edition, Directory of Open Access Journals (DOAJ), African Journal Online, Bioline International, Open-J-Gate and Pharmacy Abstracts

\section{INTRODUCTION}

Retinal vascular occlusive diseases, age-related macular degeneration of neovascularization, glaucoma and other eye diseases are closely related to retinal ischemia, and may result in severe visual impairment and blindness [1]. Glaucoma is an eye disease associated with 
visual field damage and atrophied optic nerve. It manifests clinically in irreversible loss of vision and optic disc depression. The major pathological features of glaucoma are progressive loss of RGCs and their axons [2].

RGCs are the nerve cells located in the final segment of retina, which is composed of multipolar ganglion cells involved in transmission of visual information. Glaucoma is not a simple disease. It is caused by increase in intraocular pressure, as well as oxidative stress, hemodynamic disorder, inflammation and immune response, neuron apoptosis and glial cell activation [3].

However, there are yet no effective drugs for preventing the degeneration of RGCs and retinal axons. Therefore, there is need to identify safe and effective drugs for reducing intraocular pressure so as to inhibit the progressive loss of RGCs in glaucoma. Resveratrol is a polyphenolic compound with antioxidant, anti-aging, antiinflammatory, neuroprotective and cardioprotective effects [4]. It is also an activator of NAD-dependent deacetylase sirtuin-1 (SIRT1), a ribozyme which plays an important role in oxidative stress, cell aging, neuroprotection and neuronal growth and development. It has been reported that resveratrol produced significant protective effect against I/R injury-induced damage in the retina [5]. However, the mechanism involved in this process has not been elucidated. This investigation was aimed at identifying the mechanism underlying the protective influence of resveratrol against I/Rinduced retinal damage in rats.

\section{EXPERIMENTAL}

\section{Animals}

A total of 72 healthy male SD rats were purchased from Nanjing Junke Bioengineering Co. Ltd. (production license number: SCXK, Nning 2017-0001). The rats weighed $232 \pm 28 \mathrm{~g}$, and were 8 weeks old.

\section{Main instruments and reagents}

The instruments and reagents used, and their makers/suppliers (in brackets) were: paraffin slicer (Shenyang Hengsong Technology Co. Ltd., model: HS-S7220); low temperature high-speed centrifuge (Hunan Xiangxin Instrument Co. Ltd, model: tgl-18m); electronic balance (Saiduolis Scientific Instrument Co. Ltd, model: BSA224s$\mathrm{CW}$ ); low temperature refrigerator (Dongguan Liuqin Testing Instrument Co. Ltd., model: LQ$\mathrm{TH}-150 \mathrm{~A}$ ); biological microscope (Shanghai
Yuanyuan) Ren Testing Equipment Co. Ltd, model: YRS-32; $\mathrm{H}$ \& $\mathrm{E}$ staining kit (Thermo Fisher Technology Co. Ltd, China; immunohistochemistry kit (Wuhan Moshak Biotechnology Co. Ltd); Rabbit Bax monoclonal antibody (Haihuzheng Biotechnology Co. Ltd.); Rabbit Bcl-2 polyclonal antibody (Baoao de Biotechnology Co. Ltd); rabbit caspase-3 monoclonal antibody (Shenzhen Zhenxinbosheng Biotechnology Co. Ltd), and resveratrol. A $50 \mathrm{mg} / \mathrm{mL}$ solution of resveratrol was prepared in anhydrous ethanol, and diluted to $10 \mathrm{mg} / \mathrm{mL}$ with pure water prior to administration to the rats on the basis of body weight.

\section{Establishment of animal model and grouping}

The animal experiments were carried in a laboratory with 12-h light/12-h dark cycle at $23 \pm$ $2{ }^{\circ} \mathrm{C}$ and relative humidity of $53 \pm 12 \%$. The rats were subjected to adaptive feeding for 1 week. Thereafter, they were anesthetized and placed on the operating table. The baseline intraocular pressure was measured after application of eye drops for relief of inflammation and mydriasis. Under the microscope, a needle connected to a saline bag about $150 \mathrm{~cm}$ high $(110 \mathrm{mmHg}$ pressure) was inserted into the anterior chamber of the rat eyes.

Care was taken to avoid inserting the needle into the sclera and other tissues. The syringe was opened, and changes in ocular pressure were recorded. If the surface of the eye was pale, the iris was ischemic. Moreover, blockage of blood flow to the fundus, and pale and edematous retina were indications that the rat model of $I / R$ was successfully established. This research was approved by the Animal Ethical Committee of Department of Obstetrics and Gynecology, Huangdao Hospital of Traditional Chinese Medicine, Qingdao, PR China (approval no. 201935684), and conducted according to the guidelines of Principles of Laboratory Animal Care [6].

The duration of ischemia was $1 \mathrm{~h}$. Thereafter, the saline bag was lowered to the level of the rats, the syringe was closed, the needle was removed, and the conjunctival congestion of eyeball on the ischemic side was observed. Three groups of rats were used: control, model and resveratrol groups. Control rats were fed without treatment, while rats in resveratrol group received intraperitoneal injection of resveratrol (250 $\mathrm{mg} / \mathrm{kg}$ ) at the same time point $24 \mathrm{~h}$ before establishment of I/R model, and thereafter at 15 $\min$ and at $48 \mathrm{~h}$. 


\section{Treatment indices}

Pathological changes in retina were determined histologically with $H$ \& $E$ staining. The rat eyeballs were excised and divested of connective tissue and anterior tissue. Then, the retinas were dissected out and placed on slides. The RGCs were enumerated under the microscope. Each retina was divided into three regions, and each region was counted in 5 zones, making a total of 15 regions per retina.

The expressions of caspase-3, Bax, glial fibrillary acidic protein (GFAP), cyclooxygenase-2 (COX2) and nitric oxide synthetase (iNOS) and Bcl-2 were determined using Western blotting assay.

\section{Statistical analysis}

Counting data are presented as mean \pm SD. Single factor ANOVA and LSD- $t$ test were used for comparison of measurement data. All analyses were done with SPSS version 23.0 software package. Statistical significance was assumed at $p<0.05$.

\section{RESULTS}

\section{Pathological changes in retina}

The retina of the control group was dense and ordered, with normal morphology, while the retina of the model group was thinner, with loose cells and disordered tissue structure. In contrast, the retina of the resveratrol group was thicker, with ordered tissue structure and dense cells. These results are displayed in Figure 1.
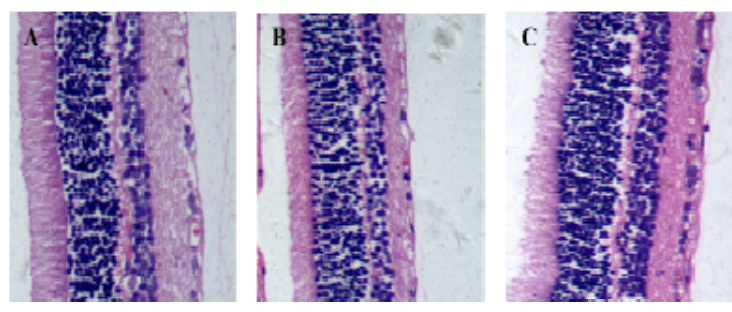

Figure 1: Pathological changes in the retina of each group. A: control; B: model; C: + resveratrol

\section{Effect of resveratrol on the population of RGCs}

As shown in Figure 2 and Table 1, compared with the control group, the number of RGCs in the retina of the model group was decreased significantly $(p<0.05)$. Compared with the model group, the number of RGCs in the retina of the resveratrol group was increased significantly $(p<$ 0.05).
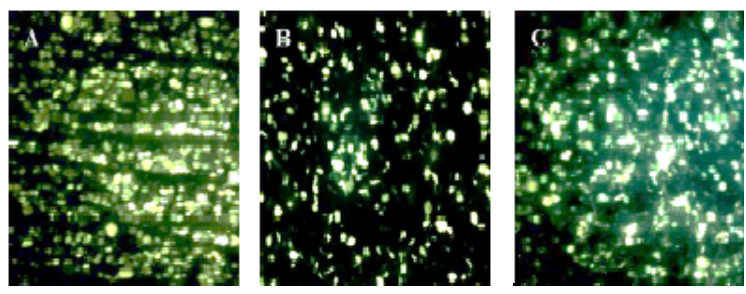

Figure 2: Effect of resveratrol on number of RGCs. A: control group; B: model group; C: resveratrol group

Table 1: Influence of resveratrol on number of RGCs

\begin{tabular}{lc}
\hline Group & No. of RGCs (quantity) \\
\hline Control & $2214.76 \pm 207.15$ \\
Model & $813.49 \pm 96.33^{\mathrm{a}}$ \\
Resveratrol & $1413.55 \pm 119.47^{\mathrm{b}}$ \\
\hline Values are mean \pm SD. ${ }^{\mathrm{a}} P<0.05$, vs control; ${ }^{\mathrm{b}} p<$ \\
0.05, vs model
\end{tabular}

Effect of resveratrol on expressions of caspase-3, Bax and Bcl-2

The results of Western blotting (Figure 3) showed that compared with the control, Bax, caspase- 3 and Bcl-2 levels in model rats were markedly upregulated, while they were significantly lower in the resveratrol-treated rats $(p<0.05)$.

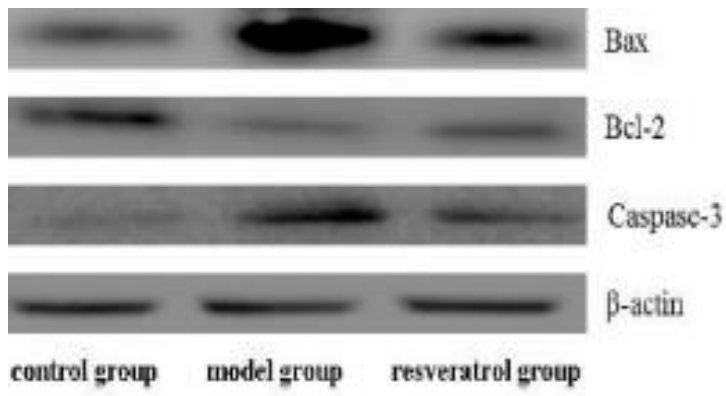

Figure 3: Levels of caspase-3, Bax and $\mathrm{Bcl}-2$ in rats

\section{GFAP expression}

Figure 4 shows marked upregulation of GFAP in model rats, relative to control rats, while resveratrol treatment downregulated GFAP, relative to model rats $(p<0.05)$.

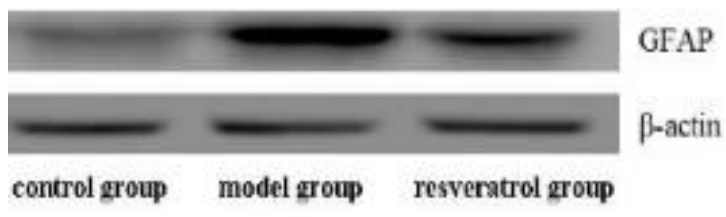

Figure 4: Expressions of GFAP in rats

Trop J Pharm Res, June 2020; 19(6): 1223 


\section{Expressions of inflammatory factors}

As shown in Figure 5, Western blotting revealed marked upregulations of COX-2 and iNOS in model rats, relative to control rats. However, resveratrol led to downregulations of COX-2 and iNOS, relative to the model group $(p<0.05)$.

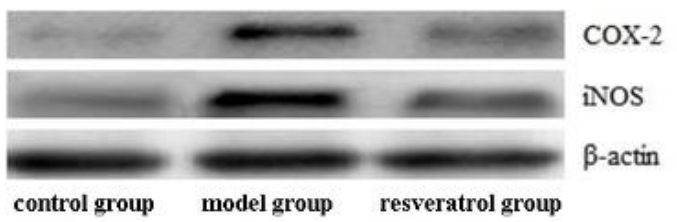

Figure 5: Expression of inflammatory factors in rats of each group

\section{DISCUSSION}

The retina is located in the medial side of the eyeball wall. It is an important tissue structure that transforms light stimulation into bioelectric signals to form visual information. However, after eyeball ischemia and hypoxia, RGCs undergo certain pathological changes which cause irreversible damage to the optic nerve, resulting in visual loss or even blindness. It has been found that the damage due to ocular ischemia and hypoxia occurs in ischemic diseases caused by occlusion of retinal artery and vein, diabetic retinopathy and glaucoma.

It has been reported that glaucoma, which results from progressive loss of RGCs, accounts for most incidents of blindness [7]. In glaucoma cases and related animal models, the increase in intraocular pressure causes compression of the optic papilla, and damages the optic nerve, glial cells, optic papilla and the connective tissue near the retinal arteriovenous system, thereby leading to optic nerve degeneration and loss of RGCs [8].

At present, the treatment outcomes for glaucoma are not satisfactory. Although intraocular pressure of glaucoma patients can be effectively controlled, the treatments do not stop the damage to the optic nerve of patients. Therefore, the search for effective anti-glaucoma drugs has continued to engage the attention of researchers. Resveratrol is a non-flavonoid polyphenol antioxidant which exists widely in peanuts, red grape and berry plants. It has anti-tumor, antiinflammatory, anti-oxidant and immune regulatory properties [9]. Some studies have found that resveratrol also exerts some neuroprotective effects, resulting in reduction of neuronal cell death, improvement of retinal vascular endothelial function, and enhancement of retinal blood flow [10].

RGCs are located in the innermost layer of the retina. They are involved in the visual acuity formation pathway. Loss of RGCS is one of the pathophysiological characteristics of ischemic eye disease [11]. Apoptosis, also known as programmed cell death, is controlled by apoptosis-related genes: Bax is the apoptosispromoting gene in Bcl-2 family, and it is the initiating factor of the internal apoptosis pathway. In contrast, $\mathrm{Bcl}-2$ is an anti-apoptotic gene which antagonizes the pro-apoptotic effect of Bax and blocks the endogenous apoptotic pathway. Caspase-3 is a cysteine proteolytic enzyme which is activated by mitochondrial-mediated endogenous pathway or receptor-mediated exogenous pathway [12]. In this study, it was found that after I/R injury, the number of RGCs in the retina was decreased significantly, while the expressions of Bax and caspase- 3 increased significantly, and the expression level of $\mathrm{Bcl}-2$ decreased significantly. Resveratrol significantly inhibited Bax and Caspase-3, as well as apoptosis of RGCs.

It has been found that the increased viability of retinal glial cells is one of the important reasons for the pathological changes in glaucoma, and also one of the important signs of retinal degeneration [13]. Glial cells are important retinal cells that regulate neuronal activity and affect neuronal survival in various kinds of injury. The GFAP is a monomeric filamentous protein which is present in astrocytes of CNS. It takes part in the biogenesis of the cytoskeleton and regulates its tensile strength. It is a marker protein for astrocyte activation [14]. In this study, resveratrol inhibited the expression of GFAP and the activation of glial cells.

Several studies have shown that inflammation is involved in the pathogenesis of glaucoma [15]. Cyclooxygenase-2 (COX-2) is a membranebound protein. Under normal conditions, COX-2 is basically not expressed, but under pathological conditions such as inflammation, COX-2 expression is significantly increased, resulting in prostaglandin E2 synthesis and production of a series of inflammatory mediators [16]. Inducible nitric oxide synthase (iNOS) is an inflammatory inducible enzyme. It has been reported that iNOS plays a role in promoting retinal degeneration in glaucoma [17]. This study revealed that resveratrol significantly inhibited COX-2, iNOS and inflammatory response. 


\section{CONCLUSION}

The results obtained in this study indicate that resveratrol protects the retina from $I / R$ injury by inhibiting RGC apoptosis, glial activation and expressions of inflammatory factors. Thus, resveratrol can potentially be used for the repair of retinal damage in humans but further studies are required ascertain this.

\section{DECLARATIONS}

\section{Conflict of interest}

No conflict of interest is associated with this work.

\section{Contribution of authors}

This study was done by the authors named in this article, and the authors accept all liabilities resulting from claims which relate to this article and its contents. The study was conceived and designed by Weiai Chen; Jinyu Xia, Xiaolu Yang, Weiai Chen collected and analyzed the data while Jinyu Xia wrote the manuscript. All authors read and approved the manuscript for publication.

\section{Open Access}

This is an Open Access article that uses a funding model which does not charge readers or their institutions for access and distributed under the terms of the Creative Commons Attribution License (http://creativecommons.org/licenses/by/ 4.0) and the Budapest Open Access Initiative (http://www.budapestopenaccessinitiative.org/rea d), which permit unrestricted use, distribution, and reproduction in any medium, provided the original work is properly credited.

\section{REFERENCES}

1. He $Y$, Liu JN, Zhang JJ, Fan W. Involvement of microRNA-181a and Bim in a rat model of retinal ischemia-reperfusion injury. Int J Ophthalmol 2016; 9(1): 33-40.

2. Burgansky-Eliash Z, Bartov E, Barak A, Grinvald A, Gaton D. Blood-Flow Velocity in Glaucoma Patients Measured with the Retinal Function Imager. Curr Eye Res 2016; 41(7): 965-970.

3. Yoshikawa M, Akagi T, Nakanishi H, Ikeda HO, Morooka $S$, Yamada $H$, Hasegawa $T$, lida $Y$, Yoshimura $N$. Longitudinal change in choroidal thickness after trabeculectomy in primary open-angle glaucoma patients. Jpn J Ophthalmol 2016; 61(1): 1-8.
4. Pirhan D, Yüksel N, Emre E, Cengiz A, Kürşat Yıldız D. Riluzole- and Resveratrol-Induced Delay of Retinal Ganglion Cell Death in an Experimental Model of Glaucoma. Curr Eye Res 2016; 41(1): 59-69.

5. Pandian S, Jeevanesan V, Ponnusamy C, Natesan S. RES-loaded pegylated CS NPS: for efficient ocular delivery. IET Nanobiotechnol 2017; 11(1): 32-39.

6. World Health Organization. Principles of laboratory animal care. WHO Chron 1985; 39: 51-56.

7. Gramlich OW, Burand AJ, Brown AJ, Deutsch RJ, Kuehn MH, Ankrum JA. Cryopreserved Mesenchymal Stromal Cells Maintain Potency in a Retinal Ischemia/Reperfusion Injury Model: Toward an off-theshelf Therapy. Sci Rep 2016; 6(1): 26463.

8. Vinod K, Gedde SJ, Feuer WJ, Panarelli JF, Chang TC, Chen PP, Parrish RK 2nd. Practice Preferences for Glaucoma Surgery: A Survey of the American Glaucoma Society. J Glaucoma 2017; 26(8): 1.

9. Seong H, Ryu J, Yoo WS, Kim SJ, Han YS, Park JM, Kang SS, Seo SW. Resveratrol Ameliorates Retinal Ischemia/Reperfusion Injury in C57BL/6J Mice via Downregulation of Caspase-3. Curr Eye Res 2017; 42(12): 1-9.

10. Luna C, Li G, Liton PB, Qiu J, Epstein DL, Challa $P$, Gonzalez P. Resveratrol prevents the expression of glaucoma markers induced by chronic oxidative stress in trabecular meshwork cells. Food Chem Toxicol 2019; 47(1): 198-204.

11. Zhang QL, Wang W, Jiang $Y$, Zhang TZ, Lu ZJ, Jiang $A$. Protective effects of a composition of Chinese herbsGurigumu-13 on retinal ganglion cell apoptosis in $D B A / 2 J$ glaucoma mouse model. Int J Ophthalmol 2018; 11(3): 363.

12. Lv B, Huo F, Dang $X, X u Z$, Chen T, Zhang T, Yang $X$. Puerarin Attenuates N-Methyl-D-aspartic Acid-induced Apoptosis and Retinal Ganglion Cell Damage Through the JNK/p38 MAPK Pathway. J Glaucoma 2016; 25(9): 792.

13. Bianchi E, Ripandelli G, Feher J, Plateroti AM, Plateroti $R$, Kovacs I, Plateroti P, Taurone S, Artico M. Occlusion of retinal capillaries caused by glial cell proliferation in chronic ocular inflammation. Folia Morphol 2015; 74(1): 33-41.

14. Unlu M, Aktas Z, Gocun PU, Ilhan SO, Hasanreisoglu M, Hasanreisoglu B. Neuroprotective effect of systemic and/or intravitreal rosuvastatin administration in rat glaucoma model. Int J Ophthalmol 2016; 9(3): 340.

15. Helin M, Rönkkö S, Puustjärvi T, Teräsvirta M, Ollikainen $M$, Uusitalo $H$. Conjunctival Inflammatory Cells and Their Predictive Role For Deep Sclerectomy in Primary Open-angle Glaucoma and Exfoliation Glaucoma. J Glaucoma 2015; 20(3): 172-178.

16. Li SY, Fung FK, Fu ZJ, Wong D, Chan HH, Lo AC. AntiInflammatory Effects of Lutein in Retinal Ischemic/Hypoxic Injury: In Vivo and In Vitro Studies. Invest Ophthalmol Vis Sci 2015; 53(10): 5976-5984.

17. Lv B, Huo F, Dang $X, X u Z$, Chen T, Zhang T, Yang $X$. Puerarin Attenuates N-Methyl-D-aspartic Acid-induced

Trop J Pharm Res, June 2020; 19(6): 1225 
Apoptosis and Retinal Ganglion Cell Damage Through the JNK/p38 MAPK Pathway. J Glaucoma 2016; 25(9):
792.

Trop J Pharm Res, June 2020; 19(6): 1226 